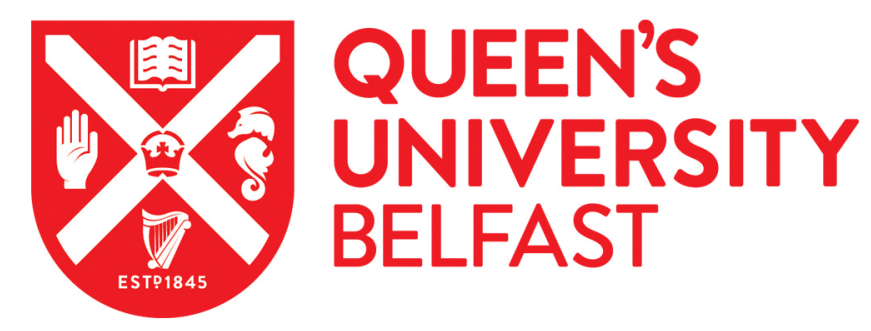

\title{
Mental health law assessments: interagency cooperation and practice complexities
}

Davidson, G., Fargas, M., Hamilton, B., Connaughty, K., Harvey, K., Lynch, G., McCartan, D., McCosker, J., \& Scott, J. (2021). Mental health law assessments: interagency cooperation and practice complexities. Journal of Mental Health, 30(1), 74-79. https://doi.org/10.1080/09638237.2019.1630721

Published in:

Journal of Mental Health

Document Version:

Peer reviewed version

Queen's University Belfast - Research Portal:

Link to publication record in Queen's University Belfast Research Portal

Publisher rights

Copyright 2019 Taylor and Francis. This work is made available online in accordance with the publisher's policies. Please refer to any applicable terms of use of the publisher.

\section{General rights}

Copyright for the publications made accessible via the Queen's University Belfast Research Portal is retained by the author(s) and / or other copyright owners and it is a condition of accessing these publications that users recognise and abide by the legal requirements associated with these rights.

Take down policy

The Research Portal is Queen's institutional repository that provides access to Queen's research output. Every effort has been made to ensure that content in the Research Portal does not infringe any person's rights, or applicable UK laws. If you discover content in the Research Portal that you believe breaches copyright or violates any law, please contact openaccess@qub.ac.uk. 
Mental health law assessments: interagency cooperation and practice

\section{complexities}

Gavin Davidson,

School of Social Sciences Education and Social Work, Queen's University Belfast,

Northern Ireland

Montserrat Fargas

School of Social Sciences Education and Social Work, Queen's University Belfast,

Northern Ireland

Bernadette Hamilton

Belfast Health and Social Care Trust, Northern Ireland

Katie Connaughty

South Eastern Health and Social Care Trust, Northern Ireland

Karen Harvey

Northern Health and Social Care Trust, Northern Ireland

Gerry Lynch

Northern Health and Social Care Trust, Northern Ireland

Delia McCartan

Southern Health and Social Care Trust, Northern Ireland

John McCosker

Western Health and Social Care Trust, Northern Ireland

Jackie Scott

Belfast Health and Social Care Trust, Northern Ireland

Corresponding author: Gavin Davidson, g.davidson@qub.ac.uk 


\title{
Accepted for publication by the Journal of Mental Health $2^{\text {th }}$ April 2019
}

\begin{abstract}
Background: Assessments under mental health law, to determine whether compulsory admission is necessary, tend to be complex, multidisciplinary and inter-agency processes. This article presents the results of a regional audit of assessments under the Mental Health (Northern Ireland) Order 1986.
\end{abstract}

Aims: The aims of the audit were to examine routine practice, identify any issues, and so inform how policy and practice may be developed.

Method: The audit was designed by an inter-agency, multi-disciplinary advisory group and audit team. Data were collected for a sample of 189 assessments. The sample was weighted to ensure all Health and Social Care Trust areas and settings were appropriately represented.

Results: These assessments involve high levels of need, risk and complexity. There were no major issues or concerns identified in the majority of assessments. The issues that were identified were mainly due to the difficulties in coordinating professionals and in securing a bed. In 3/189 (2\%) of assessments, these issues were identified as contributing to increased distress and risk.

Conclusions: The results highlight the complexities of these assessment processes and confirm the need for inter-agency interface groups to further promote cooperation and identify when pressures on resources are increasing risk and distress.

Keywords: mental health law; compulsory admission; interagency working; risk; decision-making. 


\section{Introduction}

The process of assessing whether a person should be compelled to be admitted to hospital is one of the most controversial and complex aspects of mental health practice. In Northern Ireland, the process may involve a number of people, including: the person who is being assessed; their nearest relative and other family and friends; an Approved Social Worker (ASW); a General Practitioner (GP) or other medical professional; the Police Service of Northern Ireland (PSNI); the Northern Ireland Ambulance Service (NIAS); and other mental health professionals. The need for such an assessment may arise at any time and in any setting. The criteria for an application for compulsory admission to hospital are set out in Article 4(2) of the Mental Health (Northern Ireland) Order 1986 (the Order). They are (a) "mental disorder of a nature or degree which warrants...detention in a hospital" and (b) "a substantial likelihood of serious physical harm" to self and/or others.

The process requires a medical recommendation and an application to be completed. The medical recommendation must be completed by a doctor, and the Code specifies that they "should, if at all possible, be someone who already knows the patient, and normally the patient's own GP would be the first choice" (para 2.21). The application can be completed by the person's Nearest Relative, as defined in the Order, or an ASW who must, as part of their assessment, identify and consult the Nearest Relative if possible. The proportion of applications completed by the Nearest Relative has been decreasing, from 488/1599 (31\%) of applications in 2000/1 (Mental Health Commission, 2009) to 61/1045 (6\%) in 2014/15 (Health and Social Care Board, 2016). If the decision is that admission is necessary, it is the Doctor's responsibility to identify 
a bed, and the ASW's responsibility to organise for the person to be conveyed safely to hospital.

The process can therefore involve: the coordination of a range of people and agencies; complex assessments and decision making; risk of harm; and potentially very serious implications for people's health, wellbeing, relationships and human rights. The need for this regional audit of assessments was identified following a Serious Adverse Incident which occurred during an assessment in a community setting. One of the concerns the incident raised was whether avoidable delays in the assessment process could contribute to increasing distress and risk for those involved.

The international literature on the use of compulsory admission highlights: the variation between countries; some of the key factors that may be important in the assessment process; and the outcomes of the use of compulsion. Various studies, comparing practices in different countries, have acknowledged the importance of changes over time in laws, attitudes, practices and services. Zinkler and Priebe (2002) reported a nearly 20 -fold variation in the rates of use within and between five European countries. Salize and Dressing (2004) also found a very wide range (from 6 per 100,000 in Portugal to 218 per 100,000 in Finland). Priebe et al. (2005) emphasized the importance of considering these rates in the context of the possible relationships between inpatient beds, numbers in prison and other forensic services, and alternatives in the community. Hatfield (2008) also considered the patterns of compulsory admissions over time (1996-2004) in England, and focused on social factors including: gender; life stage; resources; isolation; and alcohol/drug use. Kelly et al. (2015) have more recently highlighted the association between high rates of compulsory admissions 
and deprivation. They reported a rate of 67.7 per 100,000 in inner-city Dublin compared to the national rate in the Republic of Ireland of 38.5.

There continues to be variations between and within countries. In Northern Ireland, from $2011 / 12$ to $2015 / 16$, the number of compulsory admissions increased by 8\% from 992 to 1070 (Department of Health, 2016). In England, during the same period the number increased by $31 \% 48,631$ in $2011 / 12$ to 63,622 in $2015 / 16$. In $2015 / 16$, there was therefore a difference in rate per 100,000 between 115.7 in England (Keown et al., 2018) and 57 per 100,000 in Northern Ireland.

The stress and complexity of the decision-making processes involved in these assessments has been identified in the research literature (Galon and Wiseman, 2010; Hooff and Goossensen, 2013; Hughes et al., 2013). This is partly due to the nature of the issues being considered; decisions about a person's liberty should be ethically challenging but there are also aspects of how services are organised and resourced which may contribute to that. Bowers et al. (2003) explored the complexities of interagency working in England from the perspectives of the professionals involved and found that everyone identified the difficulty of getting the right people to the right place at the right time. Oliver-Loft and Lavender (2015) also found, based on interviews with service users and psychiatrists, that lack of continuity of care by professionals and services as a barrier to establishing the positive, trusting relationships which are particularly important in a crisis.

The final area of international research which provides the wider context for the audit is on the impact and outcomes of these assessments. Katsakou and Priebe (2006, 
2007) reviewed the literature on the quantitative and qualitative studies on the outcomes of compulsory admission. From the 18 quantitative studies they reviewed, they reported that most people who were compulsorily admitted improved over time, and retrospectively between $33 \%$ and $81 \%$ viewed their admission as justified and/or beneficial. They also identified that a substantial number of people view their experience of compulsion less positively. Berry et al. (2013) reviewed 24 studies exploring the association between admission, symptoms and trauma. They reported high levels of Post-Traumatic Stress Disorder (PTSD) resulting from the trauma of symptoms and/or hospitalisation, with prevalence rates for PTSD resulting from these traumas varying from $11 \%$ to $67 \%$. It is difficult to identify the relative contribution of symptoms and admission but compulsory intervention also has the potential to affect the person's sense of self, their relationships with others, their engagement with services, and increase problems associated with stigma and discrimination.

There has been limited previous examination of this area of health and social care in Northern Ireland (Quinn, 1992; Britton et al., 1999). Davidson and Campbell (2010) conducted an audit of assessment and reporting by ASWs and did find that there were sometimes delays in the process of assessment which impacted on the quality of care. As part of the Bamford Review of Mental Health and Learning Disability (2007), a review of the current legal framework was conducted which concluded that "having one law for decisions about physical illness and another for mental illness is anomalous, confusing and unjust" and so "...the Review considers that Northern Ireland should take steps to avoid the discrimination, confusion and gaps created by separately devising two separate statutory approaches, but should rather look to creating a comprehensive legislative framework which would be truly principles-based and non-discriminatory" (Bamford, 2007: 36). This recommendation, which is also a positive response to the UN 
Convention on the Rights of Persons with Disabilities, led to the development of the Mental Capacity Act (Northern Ireland) 2016 which will provide a non-discriminatory, legal framework, based on a functional test of decision making ability, but this will not be implemented until 2020 at the earliest and, even then, the current Order will remain in place for those aged under 16.

\section{Methods}

The aims of the audit were to examine routine practice, identify any issues, and so inform how policy and practice may be developed. The main source of standards and guidance for these assessments are the Mental Health (Northern Ireland) Order 1986, and its associated Guide (Department of Health and Social Services (DHSS, 1986) and Code of Practice (DHSS, 1992).

The design was a prospective audit of assessments for admissions under the Order. The Audit Project Team and Project Advisory Group were made up of representatives of the relevant Trusts, PSNI, NIAS, service users, carers, and the main professional groups who are involved in the process. The Project Team and Advisory Group developed the Audit Tool. It was agreed that the most appropriate source of this routinely gathered information about these assessments was the ASW report. Any information which was not contained in the report could then be collected from the relevant professionals involved. The Audit Tool was piloted using anonymised ASW reports and further refined.

The audit period was from the 1st August 2015 until the 31st October 2015. Based on the number of assessments in previous years (DHSSPS, 2013, 2014, 2015), it was calculated that a sample of 189 assessments would be needed to provide a representative sample of the total number of assessments in that period. It was agreed 
with the Project Team and Advisory Group that, as it was more likely that difficulties in the assessment process could arise in community settings, no more than a third (63) of the assessments included in the audit would have been conducted in hospital settings (with people who had already been admitted voluntarily). In the actual sample, there were $23 \%$ hospital assessments. It was also agreed that the sample should reflect the anticipated proportion of assessments being carried out in each Trust area. It was also important to ensure that assessments that were conducted both in and out of hours were also represented. In 2012/2013, approximately 25\% were conducted by the Regional Emergency Social Work Service (RESW), and in this audit, $27 \%$ of the included assessments were completed by RESW.

This project was an audit of routine practice and so ethical approval or participant consent were not required and this was confirmed by the relevant University Ethics Committee. All the necessary Health and Social Care Trust governance approval, data access, and confidentiality agreements were in place before data collection began.

The data was collected from the ASWs' reports by one of the research team (MF) on the relevant Trust site with any clarification sought from the relevant professionals. Additional information, where necessary, was also collected from the PSNI and the NIAS and the relevant professionals. Data analysis involved descriptive statistics, crosstabs to explore possible patterns, and thematic analysis of the qualitative data.

\section{Limitations}

There are a number of limitations of the audit that are important to highlight and acknowledge. It is possible that the audit period and the sample included are not representative of all assessments in the three month audit period and/or more generally 
over time. Perhaps the most important limitation of the audit design was that the main source of data was from the ASWs' reports. It would have provided a much more complete overview to have also been able to consider the perspectives of everyone involved, including the service users and carers.

\section{Results}

Data was collected for 189 assessments. Less than a quarter of all the assessments were conducted in a psychiatric hospital $(n=43 ; 23 \%)$, and the majority were conducted in the community $(n=146 ; 77 \%)$. Over a quarter $(n=51 ; 27 \%)$ were out of hours assessments. Most assessments resulted in compulsory admission $(n=155$; $82 \%)$, but there were also some voluntary admissions $(\mathrm{n}=13 ; 7 \%)$ and alternative care plans $(\mathrm{n}=21 ; 11 \%)$. The assessments were completed with 96 men $(51 \%)$ and 93 women (49\%). They were aged between 16 and 93 years old, with a mean age of 47 . Ethnicity was recorded as white for 178/189 (94\%). In terms of living arrangements: 80 (42\%) lived with family or friends; 66 (35\%) lived alone; 30 (16\%) in some form of care setting; and eight were homeless. For five, their living arrangements had not been specified. In terms of area where the service users lived, $80 \%$ lived in urban areas $(n=145)$ and $20 \%$ lived in rural areas $(n=37)$. Of the remaining seven, four were recorded as homeless and for three their living arrangements were not recorded.

The Northern Ireland Multiple Deprivation Measure (NIMDM) 2010 provides information on seven types of deprivation and an overall measure of multiple deprivation for small areas. Super Output Areas (SOA) are ordered from most deprived to least deprived on each type of deprivation and then assigned a rank. The most deprived SOA is ranked 1 and as there are 890 SOAs, the least deprived SOA has a rank of 890 . The mean rank of this sample was 346.2. The ranks were divided into quartiles 
$\left(1^{\text {st. }}\right.$ ranks $1-222 ; 2^{\text {nd. }}: 223-444 ; 3^{\text {rd }}: 445-666$; and $\left.4^{\text {th }}: 667-890\right)$, with the first quartile as the most deprived and the fourth quartile as the least deprived. Most service users lived in either the first or second rank quartiles.

Table 1. Multiple Deprivation by Trust

The majority were not employed $(n=113 ; 60 \%)$, only one in 12 were employed parttime or full-time $(n=16)$, and $18 \%$ were retired $(n=34)$. There were also six students. For 20 service users (11\%), their employment status was not specified. For most of the service users in the sample, one or more physical health problems had been identified. Some of these were: diabetes, asthma, epilepsy, chronic pain, and heart problems. For $45 \%$, no physical health problems or disabilities were known or had been reported. One in six $(n=31)$ had dependants identified (i.e. children under 18 living with them or who they had contact with).

The majority of services users were currently in receipt of services, such as Community Mental Health Teams (CMHT) $(n=105 ; 56 \%)$, psychiatrists $(n=117 ; 62 \%)$, Home Treatment Team (HTT) $(n=23 ; 12 \%)$, domiciliary $(n=6 ; 3 \%)$, or other statutory services (e.g. psychologists, 16+Team, Gateway services, Community Addictions, etc.) $(\mathrm{n}=41 ; 22 \%)$. The majority also were known (or had in the past been known) by mental health services $(n=157 ; 83 \%)$.

Most assessments were joint assessments with the ASW and GP $(n=162 ; 86 \%)$ present at the same time, as recommended in the Code of Practice 2.5. When this did not happen, ASWs were usually able to consult with GPs ( $n=24 ; 13 \%)$, mostly on the phone, but also face-to-face in some cases. In three cases, the ASWs was not able to contact the GP. The GP conducting the assessment was the service user's own GP in $39 \%$ of the cases $(n=74)$, although only three of those were for the 51 out-of-hours 
assessments.

The nearest relative was consulted in $85 \%(n=161)$ of assessments. While it was recorded that this consultation took place, it was sometimes not specified whether it was face to face or by phone. In nearly all of the cases, ASWs mentioned other sources of information, varying from other family members and friends to a range of professionals and records/information systems.

Regarding the assessment duration (from initial request for the assessment to the completion of the process), for the 152 assessments (where this information had been established), the average time spent was 5.6 hours (SD 3.6), with a maximum of 27 hours and a minimum of 1.75 . The longest assessments were those where the initial request had occurred the previous day, and it had been agreed to postpone the assessment in order to facilitate a joint assessment with the GP on the following day. The assessments involving a shorter duration, from request to completion, were usually those where conveyance was not necessary, including when the outcome was not a detention, or when the service user was already a patient in the psychiatric hospital.

The usual process of assessment involved the relevant professionals arranging a time to meet. However, in some cases, there were issues raised about: delays in being able to contact and arrange a suitable time mainly with GPs $(8 / 189 ; 4 \%)$; delay due to ASW availability $(2 / 189 ; 1 \%)$; and initial disagreements between ASWs and GPs $(2 / 189 ; 1 \%)$, or between ASWs and other professionals $(2 / 189 ; 1 \%)$.

Interviews were mostly conducted in the service users' own homes (including nursing homes, supported living accommodation, and children's residential homes) $(\mathrm{n}=95 ; 50 \%)$ and in hospitals (including mental health hospitals, general medicine hospitals, A\&E, etc.) ( $\mathrm{n}=78 ; 41 \%)$. Other locations for the interviews were: GP surgery 
$(n=6)$, relatives' home $(n=5)$, police station $(n=3)$, and other community settings $(n=2)$. Interpreters were involved in five cases. Service users were intoxicated in five cases (including two in which the service users had taken an overdose). Medical assessment and treatment, for physical health concerns, was required in 14 cases.

Police assistance was requested in 74 cases (41\%). Reasons provided for these requests mainly related to concerns for the physical safety of the patient and/or others during the assessment and conveyance process. In a small number of occasions, service users had been arrested and were in police custody (e.g. for criminal damage, threatening others) $(n=8)$. The average length of time between request for police assistance and arrival was one hour and 12 minutes (SD 1:18), with a minimum of four minutes and a maximum of five hours and 46 minutes $(n=51)$. The average length of time between police arrival and incident closed was three hours and three minutes (SD 2:42), with a maximum of 12 hours and two minutes. This information was provided by the police. In rural areas, the average length of time between the police being requested and their arrival, across 10 cases, was two hours and four minutes whereas in urban areas, for the 39 cases, the average was 59 minutes.

Issues with police involvement emerged in a small number of cases, most of them concerning delay $(n=8)$. Other issues concerned disagreements between ASW and police on how to manage the assessment and conveyance process $(n=2)$. It should be noted that these findings are based on the ASW report, and there may be different perspectives on these events. In one case, although the level of risk during assessment was very high, the police were not in attendance, as they had been given the wrong address, and it was felt this increased the level of risk.

In terms of identifying risks, ASWs identified risks to the service user and others 
in half of the reports $(n=95 ; 50 \%)$, while in a significant proportion of cases, risks were only identified to the service user $(n=79 ; 42 \%)$. In a few cases, there were no identified risks $(\mathrm{n}=9 ; 5 \%)$, or the ASWs only identified risks to others $(\mathrm{n}=6 ; 3 \%)$. The ASW reports include a specific section on the human rights issues which have been considered. It appeared from reviewing the ASW reports that some ASWs seemed to be using a generalised formula to record these considerations rather than taking an individualised approach. Most mentioned Articles 2, 5, 6 and 8 of the European Convention on Human Rights, which are part of UK law under the Human Rights Act 1998.

Ambulances were involved in $42 \%$ of all 189 cases $(n=80)$, and in eight cases the ambulance was cancelled, usually because of long waiting times, and alternative arrangements for conveyance were made. According to NIAS' records, the average length of time between the timescale agreed and that achieved was 30 minutes (SD $0: 46)$, with a minimum of zero minutes and a maximum of three hours and nine minutes. The average length of time of ambulance involvement was one hour and 15 minutes (SD 0:49), with a minimum of 15 minutes and a maximum of three hours and 50 minutes.

In $35 \%$ of the 125 assessments reviewed where conveyance was required, service users were conveyed by ambulance only. In $28 \%$ of cases, police and ambulance were involved. In 31 of these cases (25\%), a range of issues were identified regarding conveyance. These included: delays with ambulance/police service arrival/assistance; difficulties coordinating all the necessary services to be present at the same time; and difficulties in getting service users into vehicles. In 2/125 (2\%) cases, delay appeared to have contributed to service users becoming more agitated, anxious or irritable and increased the risks involved. 
Delays were not always negative. In one case, there was considerable delay but this was due to efforts, eventually successful, to persuade the person to leave their house without the use of physical force.

Beds were accessed outside the person's Trust area of residence in 15 cases $(12 \%)$. For over half of the relevant assessments $(n=70)$, there is no information recorded in the ASW report regarding who identified the bed. Where this information was specified, most of the beds were identified by the GP $(n=28 ; 21 \%)$, although ASW identified them in 23 occasions (18\%), while other professionals did in 10 other cases (8\%). Significant delay in identifying a bed was recorded in 13 of the assessments reviewed (10\% of community assessments).

\section{Discussion}

While it is not possible to directly compare the findings of this audit with the previous audit (Davidson and Campbell, 2010), which looked at all assessments in a period rather than a sample which over-sampled community assessments, there are still some interesting differences. In the previous audit, the ASW did not speak with the GP in $36 \%$ of assessments. In this audit, this had reduced to $3 / 189(2 \%)$ and there were reasons provided for each case. This is a very positive development although it does also appear to becoming more difficult for the person's own GP to be involved, especially out of hours. The level of joint assessments also increased from $49 \%$ to $86 \%$. The level of police and ambulance involvement remained approximately the same, $44 \%$ vs $41 \%$ for police involvement and $43 \%$ vs $42 \%$ for ambulance involvement. It is difficult to assess whether this level of involvement of police and ambulance is at the right level. It is also difficult to determine whether police and ambulance involvement will increase or help manage the potential trauma and risks involved and this remains a 
difficult area of professional judgement.

Although there were no issues regarding delay or increased risk identified in the audit period with assessments in which the nearest relative acted as applicant, it is still concerning that in $2014 / 15,61$ applications were completed by nearest relatives. The problems associated with the nearest relative making the application have been fully explored as part of the Bamford Review of Mental Health and Learning Disability (2007) and the need to formally end this role accepted.

There seems to be variation in who requests ambulance involvement and identifies a bed if needed. Variation in itself is not necessarily an issue but if there are differences in these processes across Trusts then, with 15/125 (12\%) of community assessments requiring a bed outside of the Trust area, additional complexities in communication may arise. There is now a Regional Bed Management Protocol which should address some of the difficulties with identifying beds across Trusts.

It is positive that the ASW reports do address the human rights issues involved in these assessments and processes including the options considered and the reasons for the final outcome. Nonetheless, the complexity of these decision making processes, by all the people involved, should certainly be further explored to ensure these crucially important processes are as unbiased and transparent as possible.

The social gradient found in the distribution of the ASW assessments also reinforces the wider importance of addressing the social determinants of mental health. It suggests that factors such as poverty should perhaps be considered as priorities for intervention to help prevent the need for compulsory admissions. 


\section{Conclusion}

It is important to acknowledge that, despite the level of need and risk involved, and the complexity of coordinating all the professionals involved, there were no issues or concerns identified in the majority of assessments considered in the audit. Although there were delays identified due to the difficulties in coordinating professionals and in securing a bed, in only $3 / 189$ (2\%) of the cases delay was identified as contributing to increased distress and risk. Nonetheless, although these are very small numbers, the potential outcomes of delay that may increase risk still makes this concerning.

There are already developments to further promote inter-agency working in this area. In one Trust an Interface Group has been established and this could provide a model for all Trusts. There are also a range of existing guidance and protocol documents which relate to these processes. Inter-agency training that facilitates interagency discussion and brings all these protocols and guidance together may be difficult to coordinate but could be beneficial. The anticipated introduction of a new legal framework, under the Mental Capacity Act (Northern Ireland) 2016, provides an excellent opportunity to further address these practice complexities.

\section{Acknowledgments}

Thanks to the Project Advisory Group; Ruth McDonald, Assistant Trust Clinical \& Social Care Governance Manager in the Lead Trust (NHSCT); and Robert Mercer, Regional Clinical Audit Facilitator for the Guidelines and Audit Implementation Network, for their advice and help throughout the project.

\section{Declaration of interest statement}

This work was funded and supported by the Guidelines and Audit Implementation 
Network (which is now part of the Regulation and Quality Improvement Authority).

\section{References}

Bamford Review (2007). A Comprehensive Legislative Framework. Belfast: Bamford Review of Mental Health and Learning Disability.

Berry, K., Ford, S., Jellicoe-Jones, L., \& Haddock, G. (2013). PTSD symptoms associated with the experiences of psychosis and hospitalisation: A review of the literature. Clinical Psychology Review, 33(4), 526-538.

Bowers, L., Clark, N. \& Callaghan, P. (2003). Multidisciplinary reflections on assessment for compulsory admission: The views of approved social workers, general practitioners, ambulance crews, police, community psychiatric nurses and psychiatrists. British Journal of Social Work, 33(7), 961-8.

Britton, F., Campbell, J., Hamilton, B., Hughes, P., Manktelow, R. \& Wilson, G. (1999). A Study of Approved Social Work in Northern Ireland. Belfast: Department of Health and Social Services.

Davidson, G., \& Campbell, J. (2010) An audit of assessment and reporting by Approved Social Workers (ASWs). British Journal of Social Work, 40(5), 1609-1627.

Department of Health and Social Services (1986). Mental Health (NI) Order 1986: A Guide. Belfast: DHSS. 
Department of Health and Social Services (1992). Mental Health (NI) Order 1986: Code of Practice. Belfast: HMSO

Department of Health, Social Service and Public Safety (2013). Hospital Statistics: Mental Health and Learning Disability (2012/13). Belfast: DHSSPS.

Department of Health, Social Service and Public Safety (2014). Hospital Statistics: Mental Health and Learning Disability (2013/14). Belfast: DHSSPS.

Department of Health, Social Service and Public Safety (2015). Hospital Statistics: Mental Health and Learning Disability (2014/15). Belfast: DHSSPS.

Department of Health (2016). Hospital Statistics: Mental Health and Learning Disability (2015/16). Belfast: DoH.

Galon, P. A. \& Wineman, N. M. (2010). Coercion and procedural justice in psychiatric care: State of the science and implications for nursing. Archives of Psychiatric Nursing, 24(5), 307-316.

Hatfield, B. (2008). Powers to detain under mental health legislation in England and the role of the Approved Social Worker: An analysis of patterns and trends under the 1983 Mental Health Act in six local authorities. British Journal of Social Work, 38(8), 15531571. 
Hooff, S. \& Goossensen, A. (2014). How to increase quality of care during coercive admission? A review of literature. Scandinavian Journal of Caring Sciences, 28(3), 425-434.

Hughes, R., Hayward, M. \& Finlay, W. M. L. (2009). Patients' perceptions of the impact of involuntary inpatient care on self, relationships and recovery. Journal of Mental Health, 18(2), 152-160.

Katsakou, C. \& Priebe, S. (2006). Outcomes of involuntary hospital admission-a review. Acta Psychiatrica Scandinavica, 114(4), 232-241.

Katsakou, C. \& Priebe, S. (2007). Patient's experiences of involuntary hospital admission and treatment: A review of qualitative studies. Epidemiologia e psichiatria sociale, 16(02), 172-178.

Kelly, B. D., Emechebe, A., Anamdi, C., Duffy, R., Murphy, N., \& Rock, C. (2015). Custody, care and country of origin: demographic and diagnostic admission statistics at an inner-city adult psychiatry unit. International Journal of Law and Psychiatry, 38, 17.

Keown, P., McBride, O., Twigg, L., Crepaz-Keay, D., Cyhlarova, E., Parsons, H., Scott, J., Bhui, K. \& Weich, S. (2016). Rates of voluntary and compulsory psychiatric inpatient treatment in England: an ecological study investigating associations with deprivation and demographics. The British Journal of Psychiatry, 209(2), 157-161. 
McKenna, B. G., Simpson, A. I., Coverdale, J. H. \& Laidlaw, T. M. (2001). An analysis of procedural justice during psychiatric hospital admission. International Journal of Law and Psychiatry, 24(6), 573-581.

Mental Health Commission for Northern Ireland (2009). Annual Report and Accounts 2008-2009. Belfast: Mental Health Commission.

Oliver Loft, N., \& Lavender, T. (2016). Exploring compulsory admission experiences of adults with psychosis in the UK using Grounded Theory. Journal of Mental Health, 25(4), 297-302.

Priebe, S., Badesconyi, A., Fioritti, A., Hansson, L., Kilian, R., Torres-Gonzales, F., Turner, T. \& Wiersma, D. (2005). Reinstitutionalisation in mental health care: comparison of data on service provision from six European countries. BMJ, 330(7483), 123-126.

Quinn, B. (1992). Social Worker: GP Liaison in Compulsory Admissions for Assessment. Belfast, DHSS.

Regulation and Quality Improvement Authority (2012). Personal correspondence received on 03/05/12 to confirm the relative proportion of applications by Nearest Relatives and Approved Social Workers under the Mental Health (Northern Ireland) Order 1986. Belfast: RQIA. 
Salize, H. J. \& Dressing, H. (2004). Epidemiology of involuntary placement of mentally ill people across the European Union. British Journal of Psychiatry, 184(2), 163-168.

Zinkler, M., \& Priebe, S. (2002). Detention of the mentally ill in Europe-a review. Acta Psychiatrica Scandinavica, 106(1), 3-8. 